\title{
Retraction Note to: Fundamental Discovery of New Phases and Direct Conversion of Carbon into Diamond and hBN into cBN and Properties
}

\author{
JAGDISH NARAYAN and ANAGH BHAUMIK
}

DOI: $10.1007 / \mathrm{s} 11661-016-3566-8$

(c) The Minerals, Metals \& Materials Society and ASM International 2016

Retraction Note to: METALLURGICAL AND

MATERIALS TRANSACTIONS A, Volume 47A, April 2016,

pp. 1481-1498

DOI 10.1007/s11661-015-3312-7

THIS article has been retracted by the Editor due to significant overlap with other publications by the same authors. Metallurgical and Materials Transactions policy does not allow for submission for publication of previously submitted or published work.

JAGDISH NARAYAN, Distinguished Professor, and ANAGH BHAUMIK, Ph.D. Student, are with the Department of Materials Science and Engineering, Centennial Campus, North Carolina State University, Raleigh, NC 27695-7907. Contact e-mails: j_narayan@ ncsu.edu; narayan@ncsu.edu

The online version of the original article can be found under doi:10.1007/s11661-015-3312-7.

Article published online May 23, 2016 